\title{
By-product recovery of Opuntia spp. peels: Betalainic and phenolic profiles and bioactive properties
}

\author{
Bruno Melgar ${ }^{\mathrm{a}, \mathrm{b}}$, Maria Inês Dias ${ }^{\mathrm{a}}$, Ana Ciric ${ }^{\mathrm{b}}$, Marina Sokovic ${ }^{\mathrm{b}}$, Esperanza M. Garcia-Castello ${ }^{\mathrm{c}}$, \\ Antonio D. Rodriguez-Lopez ${ }^{\mathrm{d}}$, Lillian Barros ${ }^{\mathrm{a}}$, Isabel Ferreira ${ }^{\mathrm{a}, *}$ \\ ${ }^{a}$ Centro de Investigação de Montanha (CIMO), ESA, Instituto Politécnico de Bragança, Campus de Santa Apolónia, 5300-253 Bragança, Portugal \\ ' University of Belgrade, Department of Plant Physiology, Institute for Biological Research "Siniša Stanković", Bulevar Despota Stefana 142, 11000 Belgrade, Serbia \\ ${ }^{\mathrm{c}}$ Institute of Food Engineering for Development, Universitat Politècnica de València, Camino de Vera, s/n CP, 46022 Valencia, Spain \\ d Institute for Industrial, Radiophysical and Environmental Safety (ISIRYM), Universitat Politècnica de València, Camino de Vera, s/n CP, 46022 Valencia, Spain
}

\section{A R T I C L E I N F O}

\section{Keywords:}

Opuntia ficus-indica

Opuntia engelmannii

By-product

Betalains

Phenolic compounds

Antimicrobial activity

\begin{abstract}
A B S T R A C T
Opuntia spp. are a tropical and subtropical plant that provides both edible green steams and fruits; however, the processing of this fruits results in the accumulation of enormous amount of by-products that can be a source of bioactive and pigmented compounds. Herein, three cactus pear from the species Opuntia ficus-indica var. sanguigna (OS) and gialla (OG) and Opuntia engelmannii (OE) were fully characterized regarding their phenolic and betalain composition and correlated with their antioxidant and antimicrobial activities. The hydroethanolic extracts of OE gave the highest amount of phenolic compounds isorhamentin- $O$-(deoxyhexosyl-hexoside) and betacianins (betanin); however, no betaxanthins were identified in this sample. This sample also revealed the lowest $\mathrm{EC}_{50}$ values in all the antioxidant activity assays. Regarding antimicrobial activity, the hydroethanolic extracts of all species revealed to be more active than ampicillin. The pivotal objective of this work was to focus on exploring by-product biocompounds and possible outputs, thus, we could suggest the use of these natural colorants with intrinsic antioxidant and antimicrobial activity, which would grant industries to produce cleaner label products with functional benefits.
\end{abstract}

\section{Introduction}

Opuntia spp., including their several varieties, belong to the dicotyledonous angiosperm and are the largest genus within Cactaceae family. Opuntia species are tropical and subtropical plants, able to grow in arid and semi-arid environments, with easy geographic adaptation due to their crassulacean acid metabolism (CAM). CAM enables the plant to survive to extreme heat, low temperatures $\left(-40{ }^{\circ} \mathrm{C}\right)$ and drought because of their highly efficiency in the use of water (Nobel, 1998; Sudzuki et al., 1993). This plant provides both edible green steams and fruits. Cactus fruit is also known as prickly pear, cactus fig, Indian fig, cactus pear, Barbary fig, and is available across the 5 continents from early summer until late autumn. Although Opuntia species are native of Mexico, where the steams and fruits are consumed fresh in the local diet, fruits, are also processed and commercialized in numerous countries as jams, sweats, ice cream and alcoholic and not alcoholic beverages (Martins et al., 2016).

Opuntia spp. crops can be found in the five continents, being Mexico the majoritarian producer of commercial prickly pear with a total cultivated area of 72,500 ha. Italy, the second largest, harvest around 3000 ha with a 70,000 $t$ yield per year. The processing of the fruits results in the accumulation of several quantities of by-products, namely prickly pear peels, which in the case of Opuntia ficus indica, accounts for around $30 \%$ of the fruit weight. In addition extensive but unknown areas of wild plants are exploited for food, feeds and materials (FAO, 2013). Proper utilization of this by-product could reduce waste disposal problems and serve as a potential new source of bioactive compounds and pigments. According to several authors (Belwal et al., 2016; GarciaCastello et al., 2015; Pinela et al., 2016; Rao, 2010), one of the best ways to use this kind of by-products could be the application of an appropriate green solid-liquid extraction technology in order to obtain bioactive compounds with different properties and health benefits. Several studies marked fruits and fruits by-products as a rich source of natural molecules such as polyphenols (i.e. flavonoids), vitamins, colorants like betalains and carotenoids (Albuquerque et al., 2016; Alzate et al., 2016; Ayala-Zavala et al., 2011; Fernandez-Rojas et al., 2010; Silva et al., 2016), which could have high potential interest in human health, medicine and production of new added-value products.

\footnotetext{
* Corresponding author.

E-mail address: iferreira@ipb.pt (I. Ferreira).
} 


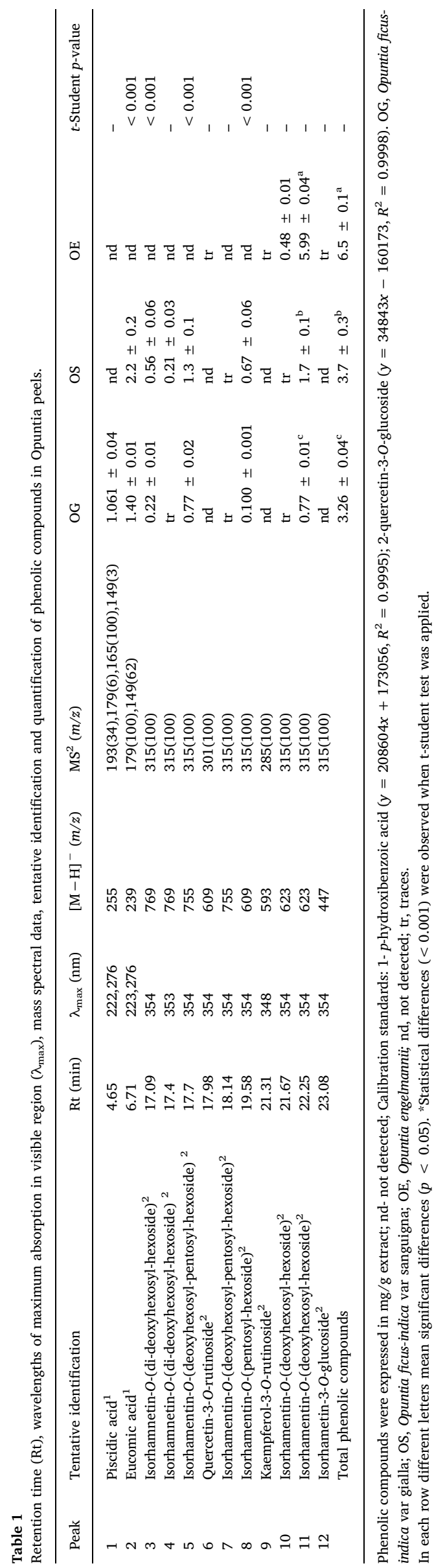

Scientists have lately reported multiple properties regarding to phenolic compounds as antioxidants endowed with anticancer, antiinflammatory, antimicrobial and antidiabetic activities (Dias et al., 2016; Kaur Kala et al., 2016). Among the most cited properties attributed to polyphenols it is the protective effect against damage of the human body caused by reactive oxygen, nitrogen and sulfur species (ROS, RNS and RSS, respectively) (Ambigaipalan, 2015; Carocho and Ferreira, 2013).

Additionally to phenolic compounds, other relevant components in the cactus pear are the betalains pigments, which are present in most of the Caryophyllales family including the Cactaceae and replace the anthocyanins in flowers and fruits of plants within this family. Betalains are water soluble nitrogen-containing pigments situated in the vacuoles of the plant tissue responsible for the red-violet (betacyanins) and yellow-orange (betaxanthins) colors, showing a stable appearance in the range of pH 3-7 (Stintzing et al., 2002). Therefore, betalains could be used as a natural colorant alternative to synthetic dyes used in a broad range of food products.

The present study intends to contribute to the characterization of the bioactive compounds profile, antioxidant and antimicrobial activities of by-products, such as peels, of the cactus pear from the species Opuntia ficus-indica var. sanguigna (OS) and gialla (OG) and Opuntia engelmannii (OE). The results of this study might be useful to maximize the potential of the fruits by-products for their colorant and functional added value.

\section{Material and methods}

\subsection{Samples preparation}

Cactus pear fruits (Opuntia ficus-indica var. sanguigna - OS and gialla - OG) were collected in July-August 2016 in Sicily, Italy and purchased from a local market in Bragança, Portugal. Fruits from this species were separated regarding the maturation colour orange-red (Opuntia ficus-indica var. gialla) and red-violet (Opuntia ficus-indica var. sanguigna), obtaining two different samples. Prickly pear wild fruits (Opuntia engelmannii- OE) were collected in Bragança, Portugal (GPS location: 41.797344, -6.772735) on early September 2016. Voucher specimens were deposited in a herbarium.

Within $24 \mathrm{~h}$, fruits were washed with distilled water in order to remove glochids and then further air-dried. Afterwards, all the fruits were peeled and the resulting peel was lyophilized (LabConco, Frezone $-105^{\circ} \mathrm{C}$, 4.5 L Cascade Benchtop Freeze Dry System, Kansas, MO, USA) and stored in a cool and dry place until use.

\subsection{Extraction procedure}

The hydroethanolic (ethanol: water, 80:20 v/v) extract was obtained from the lyophilized peels. The sample $(1 \mathrm{~g})$ was extracted twice by stirring with $25 \mathrm{~mL}$ of hydro-alcoholic solution $\left(25^{\circ} \mathrm{C}\right.$ at $\left.150 \mathrm{rpm}\right)$ for $1 \mathrm{~h}$ and subsequently filtered through the Whatman no. 4 paper. The obtained extracts were frozen, lyophilized and re-dissolved in: (i) hydroethanolic solution (ethanol: water, 80:20 v/v) for phenolic characterization (final concentration $5 \mathrm{mg} / \mathrm{mL}$ ) and antioxidant activity evaluation (final concentration $40 \mathrm{mg} / \mathrm{mL}$ ); or (ii) water for cytotoxicity evaluation (final concentration $8 \mathrm{mg} / \mathrm{mL}$ ) and betalain characterization (final concentration $30 \mathrm{mg} / \mathrm{mL}$ ); or (iii) $5 \%$ DMSO in distilled water (final concentration $10 \mathrm{mg} / \mathrm{mL}$ ) for antimicrobial assays. The final solutions were further diluted to different concentrations to be submitted for distinct in vitro bioactivity evaluation assays.

\subsection{Phenolic compounds}

The lyophilized hydroethanolic extracts were analysed for their content in phenolic compounds, re-dissolve in ethanol:water (80:20, $v$ / $v$ ) to a final concentration of $5 \mathrm{mg} / \mathrm{mL}$. LC-DAD-ESI/MSn analyses were 
Table 2

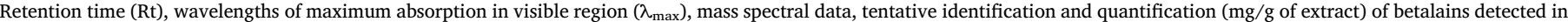
Opuntia peels.

\begin{tabular}{|c|c|c|c|c|c|c|c|c|}
\hline \multicolumn{2}{|c|}{ Peak Tentative identification } & Rt (min) & $\lambda_{\max }(\mathrm{nm})$ & {$[\mathrm{M}+\mathrm{H}]^{+}(m / z)$} & $\operatorname{MS}^{2}(m / z)$ & OG & OS & $\mathrm{OE}$ \\
\hline \multicolumn{9}{|c|}{ Betaxanthins } \\
\hline 1 & Indicaxanthin isomer I & 24.47 & 477 & 309 & $263(100), 219(43), 188(15)$ & $\begin{array}{l}\text { nq } \\
(25.3 \pm 0.4)\end{array}$ & $\begin{array}{l}\mathrm{nq} \\
(56 \pm 6)\end{array}$ & nd \\
\hline 2 & Indicaxanthin isomer II & 25.63 & 477 & 309 & 263(100),219(43),188(15) & $\begin{array}{l}\mathrm{nq} \\
(64.5 \pm 0.5)\end{array}$ & $\begin{array}{l}\mathrm{nq} \\
(2.8 \pm 0.1)\end{array}$ & nd \\
\hline \multicolumn{9}{|c|}{ Betacyanins } \\
\hline 3 & Betanidin-5-O- $\beta$-sophoroside ${ }^{1}$ & 22.76 & 534 & 713 & $551(34), 389(100), 345(3), 150(3)$ & nd & nd & $\begin{array}{l}0.98 \pm 0.02 \\
(4.88 \pm 0.01)\end{array}$ \\
\hline 4 & Betanidin-5-O- $\beta$-glucoside (betanin) ${ }^{1}$ & 23.26 & 534 & 551 & $389(100), 345(50), 150(28)$ & $\begin{array}{l}1.25 \pm 0.01^{\mathrm{c}} \\
(10.2 \pm 0.1)\end{array}$ & $\begin{array}{l}3.44 \pm 0.03^{b} \\
(36.4)\end{array}$ & $\begin{array}{l}14.9 \pm 0.3^{\mathrm{a}} \\
(77.7 \pm 0.3)\end{array}$ \\
\hline 5 & Isobetanin $^{1}$ & 24.62 & 534 & 551 & $389(100), 345(73), 150(46)$ & nd & $\begin{array}{l}0.5439 \pm 0.003 \\
(5.3)\end{array}$ & $\begin{array}{l}1.69 \pm 0.06^{*} \\
(8.6 \pm 0.1)\end{array}$ \\
\hline 6 & Gomphrenin $\mathrm{I}^{1}$ & 25.73 & 535 & 551 & $507(3), 389(38), 345(100), 301(21)$ & nd & nd & $\begin{array}{l}0.423 \pm 0.002 \\
(1.97 \pm 0.05)\end{array}$ \\
\hline \multirow[t]{2}{*}{7} & Betanidin $^{1}$ & 28.16 & 523 & 389 & 343(97),150(91) & nd & nd & $\begin{array}{l}1.36 \pm 0.07 \\
(6.9 \pm 0.2)\end{array}$ \\
\hline & Total betacyanin compounds & & & & & $1.25 \pm 0.01^{\mathrm{c}}$ & $3.97 \pm 0.03^{\mathrm{b}}$ & $19.4 \pm 0.4^{\mathrm{a}}$ \\
\hline
\end{tabular}

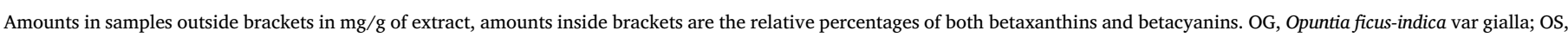
Opuntia ficus-indica var sanguigna; $\mathrm{OE}$, Opuntia engelmannii.

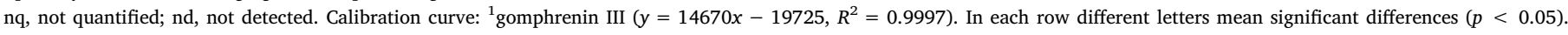
*Statistical differences $(<0.001)$ were observed when t-student test was applied.

performed using a Dionex Ultimate 3000 UPLC instrument (Thermo Scientific, San Jose, CA, USA), coupled to a diode-array detector (using several wavelengths, 280, 330 and $370 \mathrm{~nm}$ ) and to a mass detector (Linear Ion Trap LTQ XL mass spectrometer, equipped with an ESI source, ThermoFinnigan, San Jose, CA, USA). The elution gradient, chromatographic and mass spectrometer conditions were performed according to (Bessada et al., 2016). Identification was performed by comparing their fragmentation pattern, retention times and UV-vis spectra with authentic standards, when available, or by comparing the obtained information with available data from literature. When a standard was not available to quantify a phenolic compound a calibration curve of similar compound from the same phenolic group was used.

\subsection{Betalain compounds}

The profile in betalain compounds was determined by LC-DAD-ESI/ MSn (Dionex Ultimate 3000 UPLC, Thermo Scientific, San Jose, CA, USA). Chromatographic separation was achieved with a Waters Spherisorb S3 ODS-2 C18 $(3 \mu \mathrm{m}, 4.6 \mathrm{~mm} \times 150 \mathrm{~mm}$, Waters, Milford, MA, USA) column working at $35^{\circ} \mathrm{C}$. The solvents used were: (A) $0.1 \%$ trifluoroacetic acid (TFA) in water, (B) acetonitrile. The gradient elution followed these parameters: from $0 \%$ to $10 \%$ B for $15 \mathrm{~min}$, from $10 \%$ to $15 \%$ B for $5 \mathrm{~min}$, from 15 to $18 \%$ B for $5 \mathrm{~min}$, from 18 to $50 \%$ B for $8 \mathrm{~min}$, and from 50 to $0 \% \mathrm{~B}$ for $12 \mathrm{~min}$. The resulting total run time was $45 \mathrm{~min}$, using a flow rate of $0.5 \mathrm{~mL} / \mathrm{min}$. Double detection was carried out in the DAD using $480 \mathrm{~nm}$ (betaxanthins) and $535 \mathrm{~nm}$ (betacyanins), as the preferred wavelength, and in a mass spectrometer (MS). MS detection was performed using positive mode, with a Linear Ion Trap LTQ XL mass spectrometer (ThermoFinnigan, San Jose, CA, USA) equipped with an ESI source. Nitrogen served as the sheath gas (50 psi); the system was operated with a spray voltage of $4.8 \mathrm{kV}$, a source temperature of $320^{\circ} \mathrm{C}$, a capillary voltage of $39 \mathrm{~V}$. The tube lens offset was kept at a voltage of $140 \mathrm{~V}$. The full scan covered the mass range from $m / z$ 100-1500, collision energy used was 24 (arbitrary units) and data acquisition was carried out with Xcalibur ${ }^{\circ}$ data system (ThermoFinnigan, San Jose, CA, USA).

The identification of the betalain compounds (betacyanins and betaxanthins) were performed by comparing the obtained information with available data reported in the literature giving a tentative identification. For quantitative analysis, a calibration curve using an isolated compound gomphrenin III (isolated from Gomphrena globosa L.) was constructed based on the UV signal ( $\mathrm{y}=14670 \mathrm{x}-19725$, $R^{2}=0.9997$ ) (Roriz et al., 2017). The results of betacyanins were expressed as mg per $100 \mathrm{~g}$ of pulp fresh weight (FW), and the results of betaxanthins were expressed as relative percentage (\%) of their areas recorded at $480 \mathrm{~nm}$.

\subsection{Bioactive properties evaluation}

\subsubsection{Antioxidant activity assays}

Successive dilutions were made from the stock solution and submitted to in vitro assays already described by (Heleno et al., 2010) to evaluate the antioxidant activity of the samples. DPPH radical-scavenging activity was evaluated using an ELX800 microplate reader (BioTek Instruments, Inc.; Winooski, VT, USA) and calculated in percentage after $1 \mathrm{~h}$ of reaction in the dark. The reducing power (RP) assay evaluated the capacity of the extracts to reduce $\mathrm{Fe} 3+$ to $\mathrm{Fe} 2+$, measuring the absorbance at $690 \mathrm{~nm}$. In $\beta$-carotene bleaching assay, the presence of antioxidants in the samples and their capacity to neutralize the linoleate free radicals, avoids $\beta$-carotene bleaching, which can be evaluated measuring the absorbance at $470 \mathrm{~nm}$. Therefore, $\beta$-carotene bleaching inhibition was calculated using the following formula: (Absorbance after $2 \mathrm{~h}$ of assay/initial absorbance) $\times 100$. The results were expressed as $\mathrm{EC}_{50}$ values (sample concentration providing $50 \%$ of antioxidant activity or 0.5 of absorbance in the reducing power assay) for antioxidant activity. Trolox was used as positive control.

\subsubsection{Antimicrobial activity assays}

The minimum inhibitory (MIC), minimum bactericidal concentrations (MBC) and minimum fungicidal concentrations (MFC) were determined by methodologies, described by (Vieira et al., 2016).

Antibacterial activity was assayed using the following, Gram-positive bacteria: Staphylococcus aureus (ATCC 6538), Bacillus cereus (clinical isolate), Micrococcus flavus (ATCC10240), and Listeria monocytogenes (NCTC7973) and Gram-negative bacteria: Escherichia coli (ATCC 35210), Pseudomonas aeruginosa (ATCC 27853), Salmonella typhimurium (ATCC 13311), and Enterobacter cloacae (ATCC 35030) were used. Whilst for antifungal assays, the following microfungi were used: Aspergillus fumigatus (ATCC1022), Aspergillus ochraceus (ATCC12066), Aspergillus versicolor (ATCC11730), Aspergillus niger (ATCC6275), Penicillium funiculosum (ATCC 36839), Penicillium ochrochloron 


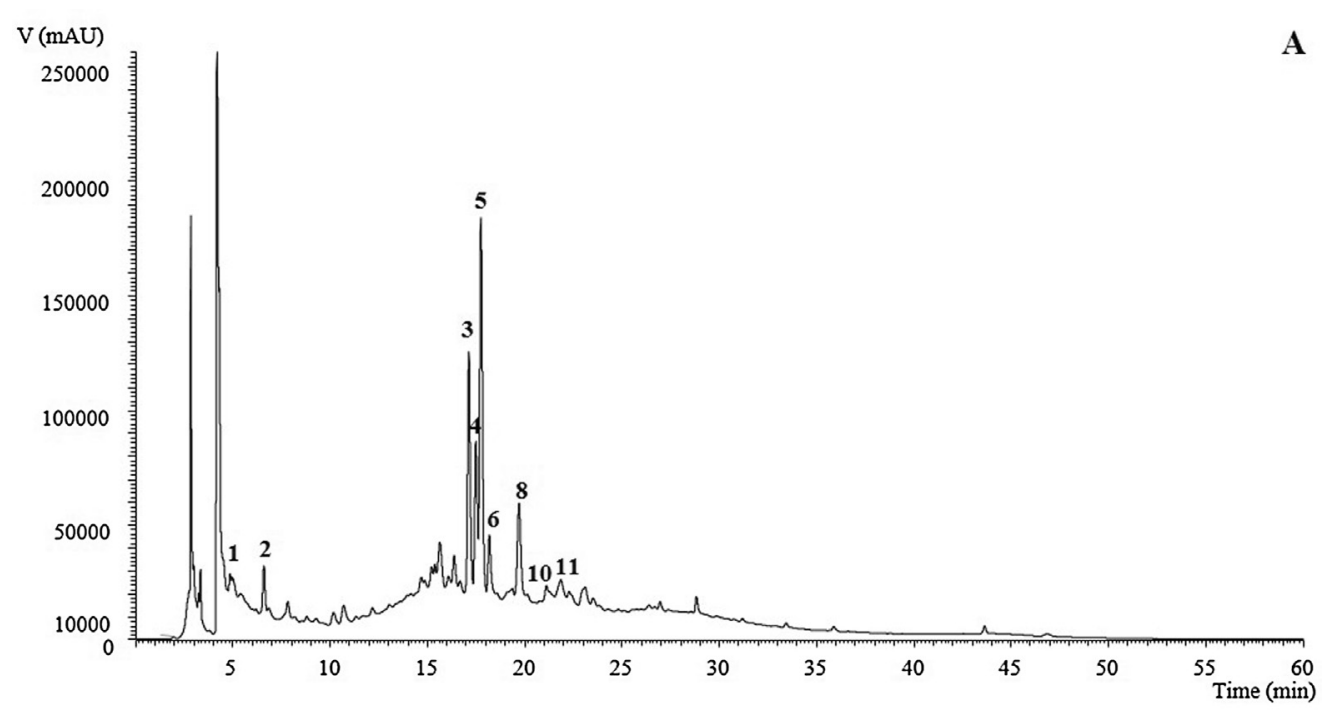

Fig. 1. HPLC chromatogram of OG phenolic profile recorded at $370 \mathrm{~nm}$ (A), betaxanthins profile of OS recorded at $484 \mathrm{~nm}$ (B) and betacyanins profile of $\mathrm{OE}$ recorded at $535 \mathrm{~nm}$ (C).
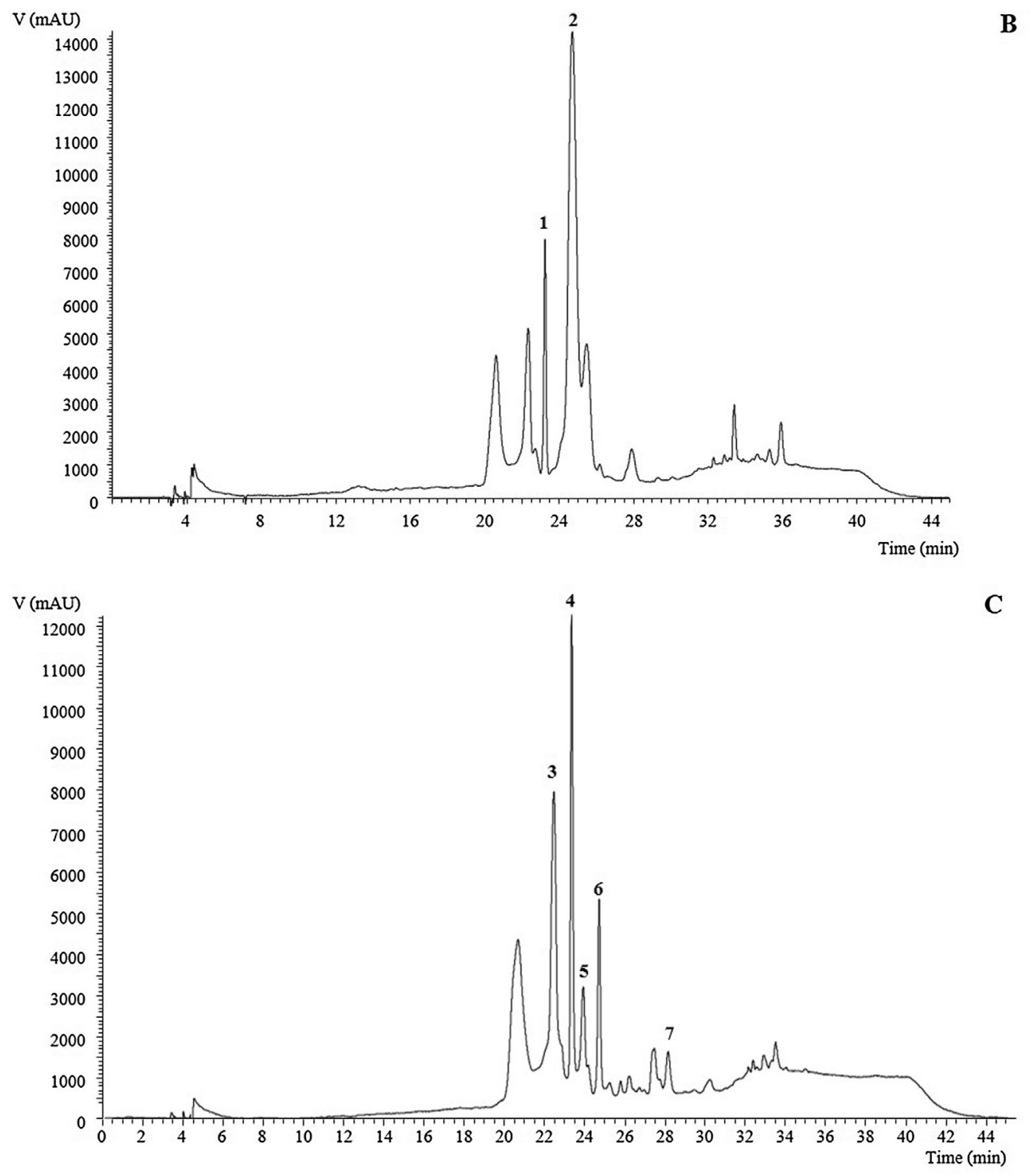
Table 3

Antioxidant activity of Opuntia peels.

\begin{tabular}{llll}
\hline $\mathrm{EC}_{50}(\mathrm{mg} / \mathrm{mL}$ extract$)$ & OG & $\mathrm{OS}$ & $\mathrm{OE}$ \\
\hline DPPH scavenging activity & $4.6 \pm 0.1^{\mathrm{a}}$ & $4.1 \pm 0.3^{\mathrm{a}}$ & $1.96 \pm 0.04^{\mathrm{b}}$ \\
Reducing power & $2.65 \pm 0.05^{\mathrm{a}}$ & $2.08 \pm 0.06^{\mathrm{b}}$ & $1.08 \pm 0.04^{\mathrm{c}}$ \\
$\beta$-carotene bleaching inhibition & $3.87 \pm 0.01^{\mathrm{b}}$ & $6.49 \pm 0.02^{\mathrm{a}}$ & $1.73 \pm 0.01^{\mathrm{c}}$ \\
\hline
\end{tabular}

$\mathrm{EC}_{50}$ values, in mg/mL extract; OG, Opuntia ficus-indica var gialla; OS, Opuntia ficus-indica var sanguigna; OE, Opuntia engelmannii. In each row different letters mean significant differences $\left(p<0.05\right.$ ). Trolox $\mathrm{EC}_{50}$ values: $62.98 \mu \mathrm{g} / \mathrm{mL}$ (DDPH), $45.71 \mu \mathrm{g} / \mathrm{mL}$ (reducing power), and $10.25 \mu \mathrm{g} / \mathrm{mL}$ ( $\beta$-carotene bleaching inhibition).

(ATCC9112), Penicillium verrucosum var. cyclopium (food isolate), and Trichoderma viride (IAM 5061). Bacterial and fungal organisms were obtained from the Mycological Laboratory, Department of Plant Physiology, Institute for Biological Research "Sinisa Stanković", University of Belgrade, Serbia. Standard drugs, namely streptomycin, ampicillin, bifonazole and ketoconazole were used as positive controls.

\subsubsection{Cytotoxicity assays}

Both, antitumor activity and hepatotoxicity was evaluated by the Sulphorhodamine B (SRB) assay that has been previously described by (Gomes-Correa et al., 2015; Pereira et al., 2014). Four human tumour cell lines were assayed: HeLa (cervical carcinoma), HepG2 (hepatocellular carcinoma), MCF-7 (breast adenocarcinoma) and NCI-H460 (nonsmall cell lung cancer), while PLP2 cells were used for hepatotoxicity. The five cell cultures were treated for $48 \mathrm{~h}$ with the different diluted sample solutions and assayed according to the SRB colorimetric methodology. Ellipticine was used as positive control and results were expressed in $\mathrm{GI}_{50}$ values in $\mu \mathrm{g} / \mathrm{mL}$ (sample concentration that inhibited $50 \%$ of the net cell growth).

\subsection{Statistical analysis}

All the extractions and assays were performed in triplicate. Results were expressed as mean values and standard deviation (SD), being analysed using one-way analysis of variance (ANOVA) followed by Tukey's HSD Test with $p=0.05$. In the case of only existing two samples, the results were analysed using a Student's $t$-test, in order to determine the significant difference between the two samples, with $p=0.05$. The treatment was carried out using IBM SPSS Statistics for Windows, version 23.0. (IBM Corp., Armonk, New York, USA).

\section{Results and discussion}

\subsection{Phenolic and betalain composition}

Tables 1 and 2 present the peak characteristics (retention time, wavelength of maximum absorption and mass spectral data), tentative identification and quantification of the phenolic compounds and betalains, respectively, present in the hydroethanolic extracts of Opuntia ficus-indica var gialla (OG), Opuntia ficus-indica var sanguigna (OS) and Opuntia engelmanniii (OE) peels (Fig. 1).

Twelve different phenolic compounds (Table 1) were found, two phenolic acids, piscid acid (peaks 1) and eucomic acid (peaks 2), and ten flavonoids (isorhamnetin, quercetin and kaempferol derivatives, peaks 3-12). All of the compounds have been previously described by other authors in Opuntia spp samples (Chahdoura et al., 2014; Chougui et al., 2015; Mata et al., 2016; Morales et al., 2015, 2014) Overall, OE sample presented higher concentration of phenolic compounds, being peak 11 (isorhamnetin-O-(deoxyhexosyl-hexoside)) the major compound found $(5.99 \mathrm{mg} / \mathrm{g})$.

Regarding betalain fractions (Table 2), seven compounds were identified; two betaxanthins, indicaxanthin isomer I and II (peaks 1 and 2), previously described by Castellanos-Santiago and Yahia (2008) in Opuntia spp. cultivars and also by Svenson et al. (2008) in Ullucus tuberosus fruits. Betalain molecules displays wide range of hues, betacyanins have reddish-violet colour while betaxanthins have a general yellow-orange colour (Albano et al., 2015; Esquivel, 2016; Gandíaherrero et al., 2013; Gandía-Herrero et al., 2010), the latter being only identified in OG and OS samples. Five betacyanins were identified, betanidin-5- $O$ - $\beta$-sophoroside, betanidin-5- $O$ - $\beta$-glucoside (betanin), isobetanin, gomphrenin I and betanidin (peaks 3, 4, 5, 6 and 7, respectively), having been previously identified by other authors (CastellanosSantiago and Yahia, 2008; Morales et al., 2015, 2014; Stintzing et al., 2002; Svenson et al., 2008). On the contrary of betaxanthins,

Table 4

Antibacterial and antifungal activity $(\mathrm{mg} / \mathrm{mL}$ of extract) of Opuntia peels.

\begin{tabular}{|c|c|c|c|c|c|c|c|c|c|c|c|c|c|c|}
\hline \multirow[t]{2}{*}{ Bacteria } & \multicolumn{2}{|l|}{ OS } & \multicolumn{4}{|c|}{ OG } & & \multicolumn{3}{|l|}{$\mathrm{OE}$} & \multicolumn{2}{|l|}{$\mathrm{C} 1$} & \multicolumn{2}{|l|}{$\mathrm{C} 2$} \\
\hline & MIC & $\mathrm{MBC}$ & & MIC & & $\mathrm{MBC}$ & & MIC & & $\mathrm{MBC}$ & MIC & $\mathrm{MBC}$ & MIC & $\mathrm{MBC}$ \\
\hline Bacillus cereus & 0.075 & 0.15 & & 0.05 & & 0.075 & & 0.10 & & 0.15 & 0.10 & 0.20 & 0.25 & 0.40 \\
\hline Micrococcus flavus & N.A. & N.A. & & N.A. & & N.A. & & N.A. & & N.A. & 0.20 & 0.30 & 0.25 & 0.40 \\
\hline Staphylococcus aureus & 0.15 & 0.45 & & 0.15 & & 0.30 & & 0.30 & & 0.45 & 0.04 & 0.10 & 0.25 & 0.45 \\
\hline Listeria monocytogenes & 0.15 & 0.60 & & 0.15 & & 0.45 & & 0.30 & & 0.45 & 0.20 & 0.30 & 0.40 & 0.50 \\
\hline Escherichia coli & N.A. & N.A. & & N.A. & & N.A. & & N.A. & & N.A. & 0.20 & 0.30 & 0.40 & 0.50 \\
\hline Enterobacter cloacae & 0.075 & 0.30 & & 0.075 & & 0.30 & & 0.10 & & 0.15 & 0.20 & 0.30 & 0.25 & 0.50 \\
\hline Pseudomonas aeruginosa & 0.15 & 0.45 & & 0.15 & & 0.45 & & 0.30 & & 0.45 & 0.20 & 0.30 & 0.75 & 1.20 \\
\hline Salmonella typhimurium & 0.15 & 0.30 & & 0.15 & & 0.45 & & 0.15 & & 0.30 & 0.25 & 0.50 & 0.40 & 0.75 \\
\hline \multirow[t]{2}{*}{ Mold } & & \multicolumn{2}{|l|}{ OS } & & \multicolumn{3}{|l|}{ OG } & \multicolumn{3}{|c|}{$\mathrm{OE}$} & \multicolumn{2}{|l|}{$\mathrm{C} 3$} & \multicolumn{2}{|l|}{$\mathrm{C} 4$} \\
\hline & & MIC & MFC & & MIC & & MFC & & MIC & MFC & MIC & MFC & MIC & MFC \\
\hline \multicolumn{2}{|l|}{ Aspergillus fumigatus } & 0.30 & 0.45 & & 0.30 & & 0.60 & & 0.30 & 0.60 & 0.25 & 0.50 & 0.15 & 0.20 \\
\hline \multicolumn{2}{|l|}{ Aspergillus versicolor } & 0.30 & 0.45 & & 0.30 & & 0.45 & & 0.30 & 0.45 & 0.20 & 0.50 & 0.10 & 0.20 \\
\hline \multicolumn{2}{|l|}{ Aspergillus ochraceus } & 0.10 & 0.15 & & 0.15 & & 0.30 & & 0.15 & 0.30 & 1.50 & 2.00 & 0.15 & 0.20 \\
\hline \multicolumn{2}{|l|}{ Aspergillus niger } & 0.30 & 0.45 & & 0.30 & & 0.45 & & 0.30 & 0.45 & 0.20 & 0.50 & 0.15 & 0.20 \\
\hline \multicolumn{2}{|l|}{ Trichoderma viride } & 0.15 & 0.30 & & 0.075 & & 0.15 & & 0.10 & 0.15 & 1.00 & 1.00 & 0.15 & 0.20 \\
\hline \multicolumn{2}{|l|}{ Penicillium funiculosum } & 0.15 & 0.30 & & 0.30 & & 0.45 & & 0.30 & 0.45 & 0.20 & 0.50 & 0.20 & 0.25 \\
\hline \multicolumn{2}{|c|}{ Penicillium ochrochloron } & 0.075 & 0.15 & & 0.075 & & 0.15 & & 0.10 & 0.15 & 2.50 & 3.50 & 0.20 & 0.25 \\
\hline \multicolumn{2}{|c|}{ Penicillium verrucosum var. cyclopium } & 0.30 & 0.45 & & 0.30 & & 0.45 & & 0.30 & 0.60 & 0.20 & 0.30 & 0.10 & 0.20 \\
\hline
\end{tabular}

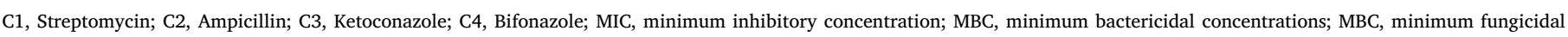
concentrations; N.A., No activity.

OG, Opuntia ficus-indica var gialla; OS, Opuntia ficus-indica var sanguigna; OE, Opuntia engelmannii. 
betacianins fraction was found in higher quantities in OE samples, being peak 4 (betanin) the main compound found ( $14.9 \mathrm{mg} / \mathrm{g}$ extract), This characteristic can be easily predicted due to the strong violet hue present in $\mathrm{OE}$ and also because betanin (betanidin-5-O- $\beta$-glucoside) is the most widespread betacyanin among plants (Esatbeyoglu et al., 2014). In this matter, betanin concentration in the analysed samples was in concordance with the previous statement commented. OE displayed differences of around 15 and 5-fold higher than OG and OS, respectively. The second highest concentration of betacyanins was conferred by isobetanin in OE and OS extracts. Only OE showed other 3 different betacyanins (betanidin, betanidin-5-O- $\beta$-sophoroside and gomphrenin I). Although, OG has this name from the Italian word "yellow", betacyanin molecule betanin, was also present but only around $10 \%$ of the total betalains detected, this pigment can be spotted as a reddish-orange hue intrinsic in OG peels.

\subsection{Antioxidant activity}

The results on antioxidant activity of the hydroethanolic extracts are shown in Table 3. There is a clear pattern in the antioxidant activity of each Opuntia spp., at first glance, $\mathrm{OE}$ exhibits the best $\mathrm{EC}_{50}$ values, followed by OS and lastly OG, nonetheless, the difference within OE $v s$ OS and OG is around 2-fold higher, while the difference among OS and OG is barely perceptible. At this point, it is worth noting the high $\mathrm{EC}_{50}$ values presented by OS in the $\beta$-carotene bleaching inhibition our hypothesis on this value could be due to an interference with the sample colour.

Independently of the $\mathrm{EC}_{50}$ values that $\mathrm{OS}$ shown in the and $\beta$-carotene assay, all the antioxidant activities of all samples, can be inversely correlated with the concentration of the betacyanins and phenolic compounds previously described in Tables 2 and 1, respectively. The relationship between betacyanins (Bc) or phenolic compounds (PC) exhibited high correlation pattern with DPPH radical scavenging activity $\left(R^{2}=-0.99\right.$ for both $\mathrm{Bc}$ and $\left.\mathrm{PC}\right)$, reducing power $\left(R^{2}=-0.97\right.$ also for Bc and PC) and $\beta$-carotene bleaching inhibition $\left(R^{2}=-0.75\right.$ for $\mathrm{Bc}$ and $R^{2}=-0.76$ for PC). Therefore, with these correlation values, very similar among the samples and there composition, can lead to possible synergistic effect between these molecules on the antioxidant activity. Several authors have suggested the positive influence of both betalains and phenolic compounds on the antioxidant activity. Cai et al. (2003) and Gandía-herrero et al. (2013) for instance, have reported that the radical scavenging properties of betalains are increased with the number of hydroxyl and imino groups. Albano et al. (2015) have also provided data related to the antioxidant activity of betalainic colorants. On the other hand, there is plethora of information related with the antioxidant effect and mechanisms of action of the phenolic compounds (Ambigaipalan, 2015; Carocho and Ferreira, 2013; Dias et al., 2016; Kaur Kala et al., 2016).

\subsection{Antibacterial and antifungal activity}

The bacteriostatic and bactericidal effects of Opuntia spp. extracts were tested against 8 different pathogenic strains (Table 4). The hydroethanolic extract exhibited effect on 6 of the 8 strains tested, being Micrococcus flavus and Escherichia coli the only resistant strains. The comparison of hydroalcoholic extracts $v s$ commercial antibiotics (streptomycin and ampicillin) were also performed and analysed. It is important to stand out the high efficiency of streptomycin $v s S$. aureus and the better efficiency shown of streptomycin $v s$ ampicillin. Nonetheless, Opuntia extracts display a higher performance against the pathogenic strains when compared with ampicillin. Although, confronting the extract $v s$ streptomycin, it was not possible to notice a good performance shown by the Opuntia extract, OG and OS were better bacteriostatic in 5 of out of 8 , while OE display equal or better strength in 3 out of 8 strain tasted. The bactericidal activity of the extracts was equal or higher in 3 out of 8 strains. OG exhibited the best performance against Bacillus cereus, while OE had stronger activity vs Enterobacter cloacae.

Regarding antifungal activity, the results obtained proved to be consistent and reproducible with the hydroethanolic extracts (Table 4). The results revealed an equal or higher performance in 4 (OS extract) and 3 (OG and OE extract) strains out of the 8 strains tested. All three samples had higher activity on Penicillium ochrochloron compared with the antifungal controls used. However, the fungicidal activity could not improve compared with fungistatic activity mention before. The Opuntia peel extracts showed equal or higher activity regarding ketoconazole or bifonazole drugs. A higher activity performance of the extract was attained on Trichoderma viride and Penicillum ochrochloron strains.

Studies from different authors attributed the inhibitory effect of plant extracts against microbial pathogens to their phenolic composition (Balouiri et al., 2016; Song et al., 2010). The inhibitory effect of these phenolics could be explained by adsorption to cell membranes, interaction with enzymes or deprivation of substrate and metal ions (Baydar et al., 2004).

\subsection{Cytotoxic activity}

Hepatotoxicity analysis were performed on the Opuntia spp. peel extracts treating PLP2 cells in order to guarantee the safety of the extracts and no toxicity was found in none of the extracts ( $\mathrm{GI}_{50}$ values $>400 \mu \mathrm{g} / \mathrm{mL}$ ). The results obtained will allow to continue studying different application of the by-product extracts in depth. Porcine liver cells were employed as the in vitro model, due to analogous physiological functioning to the human cells. Concurrently, antitumor activity was tested with four different human tumour cell lines (breast adenocarcinoma - MCF-7, non-small cell lung cancer - NCIH460, cervical carcinoma - HeLa and hepatocellular carcinoma HepG2), although the extracts displayed beneficial antitumor activity, the strength of the extracts could not overcome the antitumor activity of the ellipticine control tested (data not shown).

\section{Conclusion}

Overall, Opuntia spp. chemical characterization was able to identify the phenolic and betalainic profile inherent to the by-products (peels) of Opuntia ficus-indica and Opuntia engelmanni. This recompilation of data will bring deeper comprehension on the specific compounds related to the antioxidant and antimicrobial capacity of the extracts analysed and the absence of toxicity. The mentioned benefits make them of huge interest as a new source of functional ingredients. The pivotal objective of this work was focused on exploring by-product biocompounds and possible outputs, thus, we could suggest their use as natural colorants with intrinsic antioxidant and antimicrobial activity, which would grant industries to produce cleaner label products with functional benefits.

\section{Acknowledgements}

The authors are grateful to the Foundation for Science and Technology (FCT, Portugal) and FEDER under Program PT2020 for financial support to CIMO (UID/AGR/00690/2013) and L. Barros contract. B. Melgar thanks CONACyT for his grant (No. 329930). The authors would also like to thank Dr. Carlos Aguiar for the botanical identification of these species. The authors are also grateful to the Serbian Ministry of Education, Science and Technological Development, grant number 173032 for financial support.

\section{References}

Albano, C., Negro, C., Tommasi, N., Gerardi, C., Mita, G., Miceli, A., De Bellis, L., Blando, F., 2015. Betalains, phenols and antioxidant capacity in cactus pear [Opuntia ficus- 
indica (L.) Mill.] fruits from Apulia (South Italy) genotypes. Antioxidants 4, 269-280. http://dx.doi.org/10.3390/antiox4020269.

Albuquerque, T.G., Santos, F., Sanches-Silva, A., Beatriz Oliveira, M., Bento, A.S., Costa, H.S., 2016. Nutritional and phytochemical composition of Annona cherimola Mill. fruits and by-products: potential health benefits. Food Chem. 193, 187-195. http:// dx.doi.org/10.1016/j.foodchem.2014.06.044.

Alzate, T., González, L.M., Hincapié, D., Cardona S, S., Londoño-Londoño, B.L., JiménezCartagena, J., 2016. The profile of bioactive substances in ten vegetable and fruit byproducts from a food supply chain in Colombia. Sustain. Prod. Consum. http://dx.doi. org/10.1016/j.spc.2016.07.005.

Ambigaipalan, P., 2015. Phenolics and polyphenolics in foods, beverages and spices: antioxidant activity and health effects-a review. J. Funct. Foods 18, 820-897. http://dx.doi.org/10.1016/j.jff.2015.06.018.

Ayala-Zavala, J.F., Vega-Vega, V., Rosas-Domínguez, C., Palafox-Carlos, H., VillaRodriguez, J.A., Siddiqui, M.W., Dávila-Aviña, J.E., González-Aguilar, G.A., 2011. Agro-industrial potential of exotic fruit byproducts as a source of food additives. Food Res. Int. 44, 1866-1874. http://dx.doi.org/10.1016/j.foodres.2011.02.021.

Balouiri, M., Sadiki, M., Ibnsouda, S.K., 2016. Methods for in vitro evaluating antimicrobial activity: a review. J. Pharm. Anal. 6, 71-79. http://dx.doi.org/10.1016/j. jpha.2015.11.005.

Baydar, N.G., Özkan, G., Sağdiç, O., 2004. Total phenolic contents and antibacterial activities of grape (Vitis vinifera L.) extracts. Food Control 15, 335-339. http://dx.doi. org/10.1016/S0956-7135(03)00083-5.

Belwal, T., Dhyani, P., Bhatt, I.D., Rawal, R.S., Pande, V., 2016. Optimization extraction conditions for improving phenolic content and antioxidant activity in Berberis asiatica fruits using response surface methodology (RSM). Food Chem. 207, 115-124. http://dx.doi.org/10.1016/j.foodchem.2016.03.081.

Bessada, S.M.F., Barreira, J.C.M., Barros, L., Ferreira, I.C.F.R., Oliveira, M.B.P.P., 2016 Phenolic profile and antioxidant activity of Coleostephus myconis (L.) Rchb.f.: an underexploited and highly disseminated species. Ind. Crops Prod. 89, 45-51. http:// dx.doi.org/10.1016/j.indcrop.2016.04.065.

Cai, Y., Sun, M., Corke, H., 2003. Antioxidant activity of betalains from plants of the Amaranthaceae. J. Agric. Food Chem. 51, 2288-2294. http://dx.doi.org/10.1021/ jf030045u.

Carocho, M., Ferreira, I.C.F.R., 2013. A review on antioxidants, prooxidants and related controversy: natural and synthetic compounds, screening and analysis methodologies and future perspectives. Food Chem. Toxicol. 51, 15-25. http://dx.doi.org/10.1016/ j.fct.2012.09.021.

Castellanos-Santiago, E., Yahia, E.M., 2008. Identification and quantification of betalains from the fruits of 10 Mexican prickly pear cultivars by high-performance liquid chromatography and electrospray ionization mass spectrometry. J. Agric. Food Chem. 56, 5758-5764. http://dx.doi.org/10.1021/jf800362t.

Chahdoura, H., Barreira, J.C.M., Barros, L., Santos-Buelga, C., Ferreira, I.C.F.R., Achour, L., 2014. Phytochemical characterization and antioxidant activity of Opuntia microdasys (Lehm.) Pfeiff flowers in different stages of maturity. J. Funct. Foods 9, 27-37. http://dx.doi.org/10.1016/j.jff.2014.04.011.

Chougui, N., Djerroud, N., Naraoui, F., Hadjal, S., Aliane, K., Zeroual, B., Larbat, R., 2015. Physicochemical properties and storage stability of margarine containing Opuntia ficus-indica peel extract as antioxidant. Food Chem. 173, 382-390. http://dx.doi. org/10.1016/j.foodchem.2014.10.025.

Dias, M.I., Sousa, M.J., Alves, R.C., Ferreira, I.C.F.R., 2016. Exploring plant tissue culture to improve the production of phenolic compounds: a review. Ind. Crops Prod. 82, 9-22. http://dx.doi.org/10.1016/j.indcrop.2015.12.016.

Esatbeyoglu, T., Wagner, A., Schini-Kerth, V.B., Rimbach, G., 2014. Betanin-a food colorant with biological activity. Mol. Nutr. Food Res. 59, 36-47. http://dx.doi.org/ 10.1002/mnfr.201400484.

Esquivel, P., 2016. Handbook on Natural Pigments in Food and Beverages Industrial Applications for Improving Food Colorl. In: Carle, R., Ralf, M.S. (Eds.), Woodhead Publishing, San Pedro, Costa Rica, pp. 81-99.

FAO, 2013. Agro-industrial utilization of cactus pear. Rome.

Fernandez-Rojas, B., Ortiz-Moreno, A., Hernandez-Navarro, D., 2010. Phenolic content and its antioxidant activity of persimmon (Dyospiros kaki L.) cultivated in Mexico. J. Biotechnol. 150. http://dx.doi.org/10.1016/j.jbiotec.2010.09.289.

Gandía-Herrero, F., Escribano, J., García-Carmona, F., 2010. Structural implications on color, fluorescence, and antiradical activity in betalains. Planta 232, 449-460. http:// dx.doi.org/10.1007/s00425-010-1191-0.

Gandía-herrero, F., Cabanes, J., Escribano, J., García-carmona, F., Jiménez-atiénzar, M.,
Jiménez-atiénzar, M., 2013. Encapsulation of the most antioxidant betalains in edible matrices as powders of different colors. J. Agric. Food Chem. http://dx.doi.org/10. 1021/jf400337g.

Garcia-Castello, E.M., Rodriguez-Lopez, A.D., Mayor, L., Ballesteros, R., Conidi, C., Cassano, A., 2015. Optimization of conventional and ultrasound assisted extraction of flavonoids from grapefruit (Citrus paradisi L.) solid wastes. LWT-Food Sci. Technol. 64, 1114-1122. http://dx.doi.org/10.1016/j.lwt.2015.07.024.

Gomes-Correa, R.C., de Souza, A.H.P., Calhelha, R.C., Barros, L., Glamoclija, J., Sokovic, M., Peralta, R.M., Bracht, A., Ferreira, I.C.F.R., 2015. Bioactive formulations prepared from fruiting bodies and submerged culture mycelia of the Brazilian edible mushroom Pleurotus ostreatoroseus Singer. Food Funct. 6, 2155-2164. http://dx.doi.org/ 10.1039/C5FO00465A.

Heleno, S.A., Barros, L., Sousa, M.J., Martins, A., Ferreira, I.C.F.R., 2010. Tocopherols composition of Portuguese wild mushrooms with antioxidant capacity. Food Chem. 119, 1443-1450. http://dx.doi.org/10.1016/j.foodchem.2009.09.025.

Kaur Kala, H., Mehta, R., Tandey, R., Sen, K.K., Mandal, V., 2016. Ten years of research on phenolics (2005-2015): a status report. Pacific Sci. Rev. A Nat. Sci. Eng. 2005-2015. http://dx.doi.org/10.1016/j.psra.2016.07.002.

Martins, N., Roriz, C.L., Morales, P., Barros, L., Ferreira, I.C.F.R., 2016. Food colorants: challenges, opportunities and current desires of agro-industries to ensure consumer expectations and regulatory practices. Trends Food Sci. Technol. 52, 1-15. http://dx. doi.org/10.1016/j.tifs.2016.03.009.

Mata, A., Ferreira, J.P., Semedo, C., Serra, T., Duarte, C.M.M., Bronze, M.R., 2016. Contribution to the characterization of Opuntia spp. juices by LC-DAD-ESI-MS/MS. Food Chem. 210, 558-565. http://dx.doi.org/10.1016/j.foodchem.2016.04.033.

Morales, P., Barros, L., Ramírez-Moreno, E., Santos-Buelga, C., Ferreira, I.C.F.R., 2014. Exploring xoconostle by-products as sources of bioactive compounds. Food Res. Int 65, 437-444. http://dx.doi.org/10.1016/j.foodres.2014.05.067.

Morales, P., Barros, L., Ramírez-Moreno, E., Santos-Buelga, C., Ferreira, I.C.F.R., 2015 Xoconostle fruit (Opuntia matudae Scheinvar cv. Rosa) by-products as potential functional ingredients. Food Chem. 185, 289-297. http://dx.doi.org/10.1016/j. foodchem.2015.04.012.

Nobel, P.S., 1998. Los incomparables agaves y cactos. Trillas, México.

Pereira, E., Barros, L., Calhelha, R.C., Duenas, M., Carvalho, A.M., Santos-Buelga, C., Ferreira, I.C.F.R., 2014. Bioactivity and phytochemical characterization of Arenaria montana L. Food Funct. 5, 1848-1855. http://dx.doi.org/10.1039/c4fo00210e.

Pinela, J., Prieto, M.A., Barreiro, M.F., Carvalho, A.M., Oliveira, M.B.P.P., Vázquez, J.A., Ferreira, I.C.F.R., 2016. Optimization of microwave-assisted extraction of hydrophilic and lipophilic antioxidants from a surplus tomato crop by response surface methodology. Food Bioprod. Process. 98, 283-298. http://dx.doi.org/10.1016/j.fbp.2016. 02.002 .

Rao, G., 2010. Optimization of ultrasound-assisted extraction of cyanidin 3-rutinoside from litchi (Lichi chinensis Sonn.) fruit pericarp. Anal. Methods 2, 1166. http://dx. doi.org/10.1039/c0ay00203h.

Roriz, C.L., Barros, L., Prieto, M.A., Morales, P., Ferreira, I.C.F.R., 2017. Floral parts of Gomphrena globosa L. as a novel alternative source of betacyanins: optimization of the extraction using response surface methodology. Food Chem. 229, 223-234. http://dx.doi.org/10.1016/j.foodchem.2017.02.073.

Silva, P., Ferreira, S., Nunes, F.M., 2016. Elderberry (Sambucus nigra L.) by-products a source of anthocyanins and antioxidant polyphenols. Ind. Crops Prod. http://dx.doi. org/10.1016/j.indcrop.2016.10.018.

Song, F.L., Gan, R.Y., Zhang, Y., Xiao, Q., Kuang, L., Li, H., Bin, 2010. Total phenolic contents and antioxidant capacities of selected chinese medicinal plants. Int. J. Mol. Sci. 11, 2362-2372. http://dx.doi.org/10.3390/ijms11062362.

Stintzing, F.C., Schieber, A., Carle, R., 2002. Betacyanins in fruits from red-purple pitaya, hylocereus polyrhizus (Weber) Britton \& Rose. Food Chem. 77, 101-106. http://dx. doi.org/10.1016/S0308-8146(01)00374-0.

Sudzuki, F., Muñoz, C., Berger, H., 1993. El cultivo de la tuna (cactus pear), 1 ed. Departamento de Reproducción Agrícola. Universidad de Chile, Santiago, Santiago, Chile.

Svenson, J., Smallfield, B.M., Joyce, N.I., Sansom, C.E., Perry, N.B., 2008. Betalains in red and yellow varieties of the andean tuber crop ulluco (Ullucus tuberosus). J. Agric. Food Chem. 56, 7730-7737. http://dx.doi.org/10.1021/jf8012053.

Vieira, V., Fernandes, Â., Barros, L., Glamočlija, J., Ćirić, A., Stojković, D., Martins, A., Soković, M., Ferreira, I.C.F.R., 2016. Wild Morchella conica Pers. from different origins: a comparative study of nutritional and bioactive properties. J. Sci. Food Agric. 96, 90-98. http://dx.doi.org/10.1002/jsfa.7063. 